\title{
Germinação e Penetração de Stenocarpella macrospora em Folhas de Milho
}

\author{
Kátia R. Brunelli ${ }^{1}$, Cândido Athayde Sobrinho ${ }^{2}$, Leonardo S. Cavalcanti ${ }^{1}$, Paulo T. O. Ferreira ${ }^{1}$ \\ \& Luis E. A. Camargo ${ }^{1}$
}

'ESALQ-USP, Av. Pádua Dias, 11, Cx. Postal 9, CEP 13418-900, Piracicaba, SP, e-mail: krbrunelli@yahoo.com.br; ${ }^{2}$ Embrapa Meio Norte, Av. Duque de Caxias, 5650, Cx. Postal 01, CEP 64006-220, Teresina, PI

(Aceito para publicação em 30/11/2004)

Autor para correspondência: Kátia R. Brunelli

BRUNELLI, K.R., ATHAYDE SOBRINHO, C., CAVALCANTI, L.S., FERREIRA, P.T.O. \& CAMARGO, L.E.A. Germinação e penetração Stenocarpella macrospora em folhas de milho. Fitopatologia Brasileira 30:187-190. 2005.

\section{RESUMO}

O sucesso do estabelecimento de uma relação parasitária entre fungos e plantas, em muitos casos, depende de eventos que antecedem à infecção. Neste trabalho, as fases compreendidas entre a germinação e a penetração do fungo Stenocarpella macrospora foram analisadas por meio de microscópio eletrônico de varredura. Para tanto, plantas de milho (Zea mays) híbrido Das-8492, suscetível à mancha foliar de diplodia, foram cultivadas em casa de vegetação e inoculadas com $300 \mu \mathrm{l}$ de uma suspensão de $10^{5}$ conídios $/ \mathrm{ml}$ ao atingirem cinco-seis folhas expandidas. As amostras foram obtidas a partir de discos foliares coletados em vários momentos após a inoculação e preparadas para análise ao microscópio eletrônico de varredura. Oitenta e seis por cento dos conídios germinaram entre 12 e $15 \mathrm{~h}$ após a inoculação, ao passo que a formação dos apressórios ocorreu $18 \mathrm{~h}$ após a inoculação. A presença de uma matriz extracelular também foi observada desde a germinação até a penetração do patógeno, sugerindo a participação da mesma nos processos relacionados à patogênese.

Palavras-chave adicionais: microscopia eletrônica de varredura, infecção fúngica, Zea mays, matriz extracelular, mancha foliar de diplodia.

\begin{abstract}
Germination and penetration of Stenocarpella macrospora on maize leaves

The success of a parasitic relationship between fungal pathogens and their host plants depends on pre-infectional events. In this work scanning electron microscopy was used to study the events that occur between germination and penetration of the fungus Stenocarpella macrospora on maize (Zea mays) leaves. Plants of the hybrid Das-8492 were cultivated in greenhouse, and inoculated at the five-six leaves stage with $300 \mu \mathrm{l}$ of a conidial suspension of $10^{5}$ conidia/ $\mathrm{ml}$. Disk samples of leaf tissue were collected at different times after inoculation and prepared for analysis by scanning electron microscopy. It was verified that $86 \%$ of the conidia germinated between $12-15 \mathrm{~h}$ whereas apressoria formation occurred $18 \mathrm{~h}$ after inoculation. The presence of an extra cellular matrix also was observed during germination and penetration, suggesting that it may have a role in pathogenesis.
\end{abstract}

Additional keywords: scanning electron microscopy, infection, Zea mays, extra cellular matrix.

O processo de reação compatível entre um fungo patogênico e seu hospedeiro inicia-se com a deposição do esporo sobre o tecido suscetível, sua germinação, formação e crescimento do tubo germinativo e o surgimento de estruturas que participam da penetração (Wynn, 1981). Os eventos decorridos entre a germinação e a penetração compreendem a fase de pré-penetração (Agrios, 1997). Esta fase merece extensiva atenção, visto que seu entendimento pode esclarecer como as plantas são infetadas, colaborando, desta maneira, na definição de estratégias que impeçam ou dificultem a penetração do patógeno. Um exemplo clássico do uso deste conhecimento está na obtenção de variedades de trigo (Triticum aestivum L.) resistentes ao fungo Puccinia graminis f. sp. tritici Erikss. \& Henning. Esporos deste fungo são liberados durante as primeiras horas da tarde, germinam durante a noite e penetram através dos estômatos durante as primeiras horas da manhã. De posse destes dados, foi possível desenvolver variedades de trigo cuja abertura dos estômatos ocorre em horas mais avançadas da manhã, permitindo que os raios do sol dessequem os frágeis tubos germinativos (Pascholati \& Leite, 1995).

O fungo Stenocarpella macrospora (Earle) Sutton [Sin. Diplodia macrospora Earle in Bull.] é um patógeno necrotrófico do milho (Zea mays L.), associado ao complexo das podridões de colmo e espiga. Em híbridos suscetíveis, pode causar grandes lesões foliares (Latterell \& Rossi, 1983) diminuindo a área fotossintetizante e funcionando como fonte de inóculo para as infecções de colmo e espiga. Sua distribuição geográfica é restrita a regiões com clima tropical e subtropical, em áreas mais quentes e úmidas (Johann, 1935). No Brasil, este patógeno foi relatado pela primeira vez em 1935 causando podridões de espigas (Johann, 1935). Sua 
K.R. Brunelli et al.

importância econômica sempre foi associada aos danos causados pelas podridões de colmo e espiga, mas nos últimos anos tem aumentado a incidência de lesões foliares associadas a esse fungo. A dispersão de $S$. macrospora a longas distâncias é viabilizada através de sementes infetadas. A curtas distâncias, chuvas associadas a ventos podem facilitar a retirada e disseminação dos conídios de seus picnídios (Shurtleff, 1992). Temperaturas entre 25 e $32{ }^{\circ} \mathrm{C}$ (Eddins, 1930) com umidade relativa acima de 50\% (Latterell \& Rossi, 1983) são condições ideais para liberação e germinação dos conídios.

Os eventos ocorridos durante as fases de pré-penetração e penetração têm sido estudados com o auxílio da microscopia eletrônica de varredura (Kropp et al., 1999, Van de Graaf et al., 2002), inclusive em patossistemas envolvendo espécies do gênero Stenocarpella, como S. maydis (Berck.) Sutton [Sin. D. maydis (Berck.) Sacc.] em sementes de milho e aveia (Avena sativa L.) (Murphy et al., 1974). Quanto a $S$. macrospora, não existem estudos sobre as fases inicias da infecção foliar em milho. Assim, este trabalho objetivou investigar e elucidar os eventos ocorridos durante os processos de pré-penetração e penetração desta espécie em tecidos foliares de um híbrido suscetível de milho.

Foram utilizadas plantas do milho híbrido Das-8492 (Dow AgroSciences), cultivadas em vasos contendo substrato esterilizado na proporção 1:1 (solo:areia). Este híbrido, em estudos anteriores realizados pela empresa, foi classificado como suscetível ao patógeno, obtendo nota entre 5-6, numa escala de 1 (sem sintoma) a $9(75 \%$ do tecido foliar colonizados pelo patógeno). As plantas foram mantidas em casa de vegetação no campo experimental do Departamento de Entomologia, Fitopatologia e Zoologia Agrícola da ESALQ-USP (Piracicaba-SP), durante 30 dias, sob temperatura entre 28 e $32{ }^{\circ} \mathrm{C}$ e condições naturais de fotoperíodo, até atingirem o estádio vegetativo de cinco a seis folhas totalmente expandidas.

O isolado de $S$. macrospora, utilizado neste ensaio, foi obtido a partir de isolamento direto de folha do híbrido Das-8432 com sintoma da doença, coletada em campo de produção no município de Rio Verde, GO. O cultivo do patógeno foi realizado em placas de Petri Pyrex ${ }^{\circledR}$ contendo meio aveia-ágar ( $20 \mathrm{~g}$ de farinha de aveia, $17 \mathrm{~g}$ de ágar e $1.000 \mathrm{ml}$ de água destilada), sob temperatura de $27^{\circ} \mathrm{C}$ com fotoperíodo $12 / 12 \mathrm{~h}$ (luz/escuro), por 30 dias, quando foi observada abundante produção de picnídios. As colônias fúngicas receberam $5 \mathrm{ml}$ de água destilada/esterilizada e foram gentilmente raspadas com o auxílio de uma lâmina de vidro para o rompimento dos corpos de frutificação e liberação dos conídios. A suspensão obtida foi filtrada com o auxilio de gaze fina e sua concentração ajustada para $10^{5}$ conídios $/ \mathrm{ml}$.

A inoculação foi realizada na quinta folha completamente expandida, que recebeu, previamente, dois gabaritos de acrílico, sendo um na parte abaxial da folha, contendo um orifício central de $0,7 \mathrm{~cm}$ de diâmetro, e o outro na superfície oposta, sem conter nenhuma perfuração, servindo apenas de apoio para fixação do primeiro. Tal orifício recebeu $300 \mu \mathrm{l}$ da suspensão de esporos, sendo imediatamente vedado com fita adesiva. Esta metodologia, além de permitir a localização exata do ponto de inoculação, também favorece a formação de filme contínuo de água, condição ideal para muitas espécies fúngicas iniciarem o processo infetivo em seu hospedeiro. As plantas foram mantidas sob as mesmas condições de cultivo, já descritas previamente, durante todo o tempo de execução do experimento.

As coletas foram realizadas às $12,15,17,21,24,27$, 30 e $33 \mathrm{~h}$ após a inoculação, totalizando oito tratamentos. O procedimento teve início com o corte da área do tecido foliar inoculado e posterior transferência dos mesmos para microtubos de $1,5 \mathrm{ml}$ contendo $500 \mu \mathrm{l}$ de solução fixadora de Karnovsky modificada $(2,5 \%$ de glutaraldeído e $2,5 \%$ de formaldeído em tampão cacodilato de sódio $0,05 \mathrm{M}$ - $\mathrm{pH} 7,2 \mathrm{e}$ $\mathrm{CaCl}_{2} 0,001 \mathrm{M}$ ). As amostras foram armazenadas a $5{ }^{\circ} \mathrm{C}$ por $24 \mathrm{~h}$, sendo em seguida processadas segundo a metodologia adaptada de Kitajima \& Leite (1997). Para tal, foram realizadas três lavagens de $10 \mathrm{~min}$. cada com tampão cacodilato de sódio $0,05 \mathrm{M}(\mathrm{pH} 7,2)$ e posterior imersão em solução de tetróxido de ósmio $1 \%$ (1\% de tetróxido de ósmio em $0,05 \mathrm{M}$ de cacodilato de sódio) por $1 \mathrm{~h}$ a temperatura ambiente. Após a fixação no ósmio, foram realizadas lavagens em água destilada e em soluções de concentrações crescentes de acetona (10, 50, 70, 90 e 100\%) durante $10 \mathrm{~min}$. Ao final, mais duas imersões em acetona $100 \%$ foram realizadas para garantir a total desidratação dos tecidos. Após este passo, iniciou-se a secagem ao ponto crítico, através da imersão das amostras em gás carbônico líquido, em aparelho Balzers modelo CPD 030, com posterior fixação e metalização com ouro em equipamento Balzers modelo MED 010. As amostras foram visualizadas em microscópio eletrônico de varredura (MEV) da marca Zeiss modelo DMS 940A.

Durante a observação dos espécimes, foram utilizados aumentos que variaram de 200 a 5.000 vezes de acordo com o detalhamento exigido. Para definir o intervalo de tempo requerido pelo processo germinativo e para a formação de apressórios foram amostrados aleatoriamente 50 conídios em cada tratamento (tempo de coleta). Como conídio germinado considerou-se aquele cujo comprimento do tubo germinativo mostrou-se igual ou superior à metade de seu próprio comprimento.

Após $12 \mathrm{~h}$ da inoculação, $56 \%$ dos esporos mostravamse ainda não germinados (Figura 1A), enquanto que após 15 h, $86 \%$ deles já apresentavam razoável elongação do tubo germinativo (Figuras 1B e 1C). Desta forma, infere-se que sob alta umidade relativa e temperatura entre 28 e $32{ }^{\circ} \mathrm{C}$ a germinação dos esporos de $S$. macrospora ocorre entre 12 e $15 \mathrm{~h}$ após a sua deposição no tecido hospedeiro.

Apressórios foram observados após $24 \mathrm{~h}$ da inoculação (Figura 1D e 1E). Dos 50 conídios observados ao acaso, 12\% deles apresentavam tal estrutura, indicando que a partir de $24 \mathrm{~h}$ do contato conídio/tecido suscetível, o fungo passa a diferenciar seu tubo germinativo em estruturas de penetração. A formação de apressórios na superfície foliar intacta é forte 

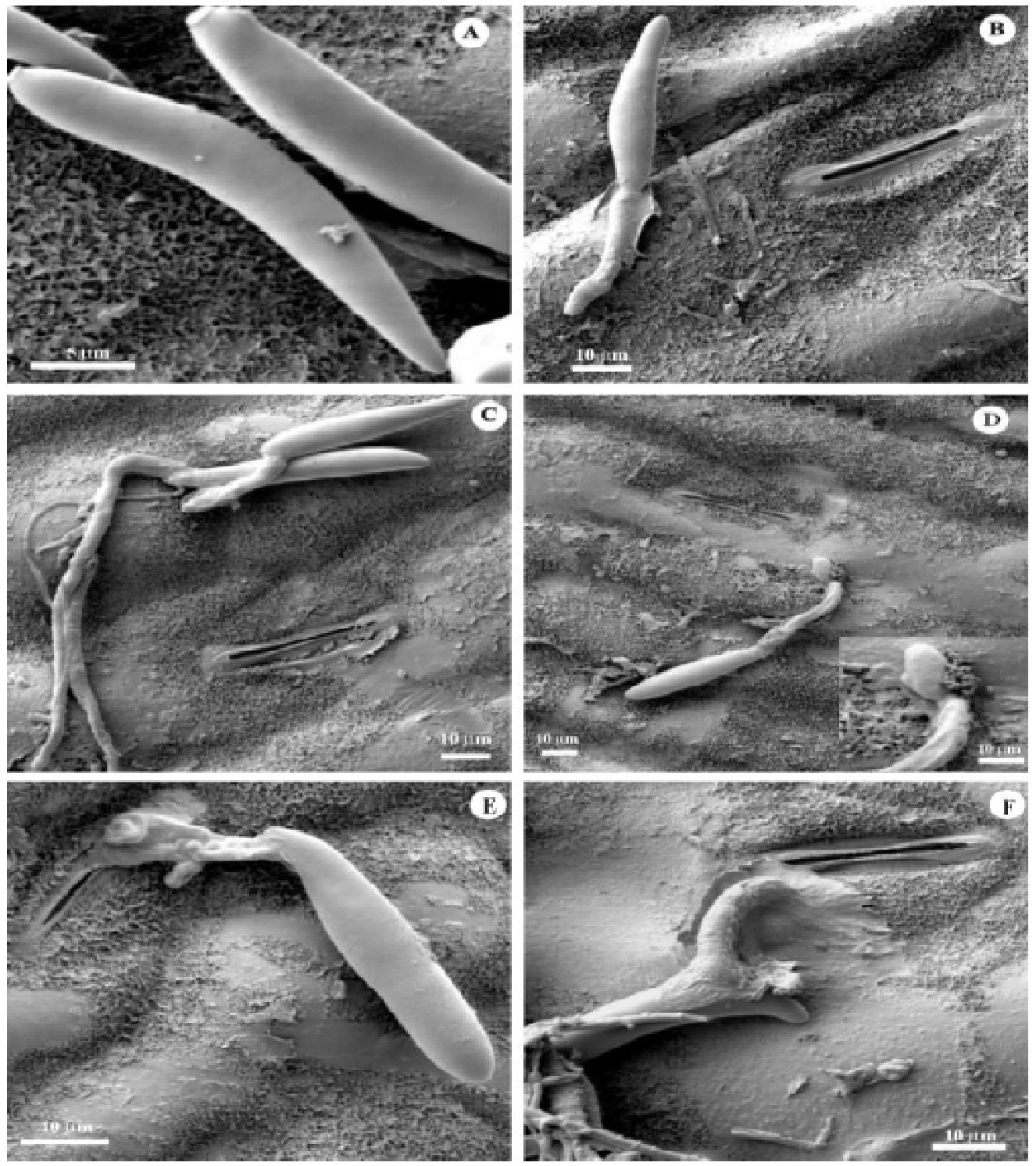

FIG. 1 - Germinação e penetração de Stenocarpella macrospora em tecido foliar de milho (Zea mays) híbrido Das-8492. A - esporos não germinados após $12 \mathrm{~h}$ da inoculação; B e C - elongação do tubo germinativo em 15 e $18 \mathrm{~h}$ após a inoculação, respectivamente; D e E - estrutura de penetração similar a apressório 24 h após a inoculação; F e G - penetração via estômato. Presença da matriz amorfa recobrindo o tubo germinativo, conídio e tecido foliar em B e G.

indicativo da penetração do fungo através da epiderme foliar. As observações de Bensch \& Van Staden (1992) com S. maydis parecem apoiar esta afirmativa. Através de estudos de microscopia de transmissão, estes pesquisadores observaram a degradação das células no ponto de contato da hifa com a superfície intacta, comprovando que a penetração direta ocorre e que é auxiliada pela ação de enzimas liberadas pelo fungo no tecido hospedeiro (BeMiller et al., 1969). Por outro lado, aqueles autores relataram que a formação de apressórios ocorreu apenas $43 \mathrm{~h}$ após a inoculação. Desta forma, $S$. macrospora parece ser mais eficiente na penetração quando comparada a $S$. maydis. Isso corrobora a observação realizada por Latterell \& Rossi (1983), para os quais S. macrospora possui maior agressividade do que $S$. maydis nos estádios de infecção e colonização, tanto em folha, quanto em espigas e colmo.

No tempo de $27 \mathrm{~h}$ também foi possível verificar a penetração dos tubos germinativos de $S$. macrospora em estômatos abertos da hospedeira (Figuras 1F e 1G). Deste modo, a formação de apressórios sobre a superfície intacta e a penetração na abertura estomática demonstram a habilidade do fungo em penetrar os tecidos suscetíveis tanto diretamente (tecido foliar intacto) quanto por aberturas naturais.

Neste trabalho, verificou-se também a formação de uma matriz amorfa recobrindo todo o tubo germinativo, parte dos conídios e estendendo-se até o tecido foliar. Essa substância 
K.R. Brunelli et al.

foi observada durante os primeiros momentos da germinação (15 h de incubação) e também nos estádios mais avançados do processo de pré-penetração (Figuras $1 \mathrm{~B}$ e $1 \mathrm{G}$ ). A presença de matriz extracelular semelhante à encontrada neste trabalho tem sido relatada em diversas interações planta-fungo (Mims et al., 1995; Kropp et al.; 1999; Van de Graaf et al., 2002), inclusive na espécie $S$. maydis (Bensch \& Staden, 1992), sendo-lhe atribuída vários papéis na patogênese. Trabalhos correlacionaram a presença de uma fina camada de mucilagem extracelular à adesão de conídios de Uncinuliella australiana (Mc Alpine) U. Braun \& S. Takam na superfície de Lagerstroemia indica L (Mims et al., 1995) e de Erysiphe graminis f. sp. avenae É.J. Marchal em folhas de aveia (Carver et al., 1995). Kropp et al. (1999) também observaram a presença de uma mucilagem recobrindo o tubo germinativo de esporos de Puccinia thlaspeos C. Schub. em folhas de ísatis (Isatis tinctoria L.) ao redor do apressório, no ponto de contato com o tecido hospedeiro. Estes autores notaram que tal substância tornou-se escurecida durante os estádios mais avançados da pré-penetração e destacaram uma ação química e mecânica da mesma na ruptura do tecido epidérmico, no ponto de contato do apressório. Bensch \& Van Staden (1992) especularam que a presença de densa mucilagem recobrindo os apressórios de $S$. maydis no ponto de infecção de fragmentos de colmo de milho, poderia estar associada à proteção dos mesmos contra a desidratação. Embora a literatura aponte que tal substância pode desempenhar um papel vital na patogênese, mais estudos são necessários para elucidar o papel da matriz no ciclo de vida do patógeno. Este é o primeiro relato da presença de mucilagem associada aos conídios de S. macrospora.

\section{AGRADECIMENTOS}

Os autores agradecem a valiosa colaboração do Prof. Elliot Watanabe Kitajima (NAP-MEPA - ESALQ-USP).

\section{REFERÊNCIAS BIBLIOGRÁFICAS}

AGRIOS, G.N. Plant Pathology. 4th ed. San Diego. Academic Press. 1997.
BeMILLER, J.N., TEGTMEIER, D.O. \& PAPELLIS, A.J. Effects of phenolics and indol-3-acetic acid on production and activity of cellulolytic and pectinolytic enzymes of Diplodia zeae. Phytopathology 59:674-676. 1969.

BENSCH, M.J. \& VAN STADEN, J. Ultrastructural histopathology of infection and colonization of maize by Stenocarpella maydis (=Diplodia maydis). Journal of Phytopathology 136:312-318. 1992.

CARVER, T.L.W., THOMAS, B.J. \& INGERSON-MORRIS, S.M. The surface of Erysiphe graminis and the production of extracellular material at the fungus-host interface during germinating and colony development. Canadian Journal of Botany 79:272-287. 1995.

EDDINS, A.H. Dry rot of corn caused by Diplodia macrospora Earle. Phytopathology 20:439-448. 1930.

KITAJIMA, E.W. \& LEITE, B. Curso introdutório de microscopia eletrônica de varredura. Piracicaba: NAP/MEPA, 1997. 46p. (Apostila do $25^{\circ}$ curso de microscopia eletrônica de varredura).

KROPP, B.R., HOOPER, G.R., HANSEN, T.R., BINNS, M. \& THOMSON, S.V. Initial events in the colonization of dryer's woad by Puccinia thlaspeos. Canadian Journal of Botany 77:843-849. 1999.

LATTERELL, F.M. \& ROSSI, A.E. Stenocarpella macrospora (=Diplodia macrospora) and S. maydis $(=D$. maydis $)$ compared as pathogens of corn. Plant Disease 67: 725-729. 1983.

MIMS, C.W., LILJBKELKE, K.A. \& RICHARDSON, E.A. Surface morphology, wall structure, and initial adhesion of conidia of the powdery mildew fungus Uncinuliella australiana. Phytopathology 85:352-358. 1995

MURPHY, J.A., CAMPBELL, L.L. \& PAPPELIS, A.J. Morphological observations of Diplodia maydis on synthetic and natural substrates as revealed by scanning electron-microscopy. Applied Microbiology 27:232-250. 1974.

PASCHOLATI, S.F. \& LEITE, B. Hospedeiro: mecanismos de resistência. In: Bergamin Filho, A., Kimati, H. \& Amorim, L. (Eds.) Manual de Fitopatologia: princípios e conceitos. São Paulo. Ceres. 1995. pp.417-453.

SHURTLEFF, M.C. Compendium of corn diseases. Minnesota. APS Press. 1992.

VAN DE GRAAF, P., JOSEPH, M.E., CHARTIER-HOLLIS, J.M. \& O'NEILL, T.M. Prepenetration stages in infection of clematis by Phoma clematidina. Plant Pathology 51:331-337. 2002.

WYNN, W.K. Tropic and taxic responses of pathogens to plants. Annual Review of Phytopathology 19:237-255. 1981. 